\title{
THE APPLICATION OF METALLURGICAL TECHNOGENIC PRODUCTS AS RAW MATERIALS FOR ROAD CONSTRUCTION MATERIALS
}

\author{
Goncharova Margarita Alexandrovna \\ Karaseva Olga Victorovna \\ Zagorulko Maxim Grigorievich \\ Lipetsk State Technical University, Russia
}

\begin{abstract}
The possibility is established of intensifying the processes of structure formation and improving the properties of asphalt concrete compositions due to the use of converter slags in them. The possibility of obtaining asphalt concretes on porous slag aggregates with the use of metallurgical waste as a mineral dust was confirmed. The research show the possibility of reducing the consumption of bitumen to $6 \%$ in asphalt concretes on porous slag aggregates. The research justifies the technology of using converter slags in road fills and bases, in asphalt concretes together with the "Recommendations on the technology of using converter slags in the structural elements of road pavement from asphalt concrete." The investigated aggregates from powder waste of local industry meet the requirements of the regulatory documentation and can be recommended for the application in asphalt concretes. This makes it possible to utilize finely dispersed industrial waste, which contributes to the reduction of environmental pollution of the industrial zone, of groundwater and of the atmosphere with land waste products and waste run-off products.
\end{abstract}

Keywords: asphalt concrete, converter slag, hardening system, physical and chemical properties, road construction

\section{INTRODUCTION}

The consumption of material resources in road construction is extremely large. The reduction of road construction materials demand and the increase of their utilization efficiency remains an urgent problem. Long-term scientific research and road construction practices have shown that a way to solve the problem is the application of industrial waste as a technogenic raw material. Such waste includes slags and other waste from pyrometallurgical processes.

Road construction with the application of slag materials was performed in different regions of Russia, especially in areas with a shortage of traditional road construction materials (crushed stone, sand, cement).

Research is conducted in the following applied areas:

- use of slag as a substitute for sand in the lower layers of bases;

- use of slag sand and crushed stone mix in the construction of crushed stone bases;

- use of sand and mineral fines in preparing asphalt concrete mixtures (Bondarev, et al., 2016; Chernyshov, 2009; Goncharova, 2015; Goncharova, 2015).

Metallurgical waste is a significant reserve of providing the construction industry with aggregates for concrete. Due to their specific characteristics, converter slags are rarely used as sand and crushed stone. Insufficient volumes of their application are mainly the result of silicate decomposition and metal content up to $10 \%$. It should be noted that converter slags were used in road construction before. However, the results of the survey of constructed sections of roads demonstrated a considerable dispersion of physical and mechanical characteristics of asphalt concrete, which testifies to the absence of scientific consistency in applying such slags in the road construction industry (Goncharova, 2015; Goncharova, 2009; Goncharova, 2005; Goncharova, 2012; Fakoor, 2015). 


\section{METHODOLOGY}

Following the research, a technological scheme was proposed for processing converter slags. According to this scheme, slags stored in dumps for more than three years are subject to fractionation with the release of 0$5 \mathrm{~mm}$ and 5-20 mm particles, the former being used as sand and mineral dust in general purpose composites and the latter- as a material for the construction of bases and reinforced structural layers of road pavements. The slag stored in dumps for less than three years is also fractionated at the initial stage: the 0-10 mm fraction is used in hardening systems, while the fraction $>40 \mathrm{~mm}$ is crushed. Crushed products are used in the mineral part of asphalt concretes or in bases and fills up to $15 \mathrm{~m}$ in height (Fakoor, et al., 2016; Goncharova, 2016; Goncharova, 2017; Goncharova, 2016).

It should be noted that the obtained strength values are $1.5 \ldots 2$ times higher than the strength required by regulatory documents, which testifies to the high quality of the obtained asphalt concrete of the optimum composition. Maximum strength is achieved at $8 \%$ bitumen content in the mixture with water absorption values being within the limits required by GOST $(1.5 \ldots 4 \%)$ for dense asphalt concretes. A further increase in its amount will lead to a decrease in strength, because after full solidification and due to shrinkage, bitumen forms microflaws that reduce strength.

\section{RESULTS}

The structure of converter slags as well as their physical and chemical properties are potentially capable of providing a sufficiently intensive interaction between slag and bitumen (Goncharova, 2008; Goncharova, 2014; Khodayari Bavil and Razavi, 2017; Khosravi, et al., 2015). It was revealed that the application of fine converter slags makes it possible to obtain activated mineral dust. Converter slags were introduced into the composition of asphalt concrete mix and of stone mastic asphalt both in their natural and activated forms. The test results demonstrated compliance of all indicators with regulatory requirements. It is known that fine-grained production waste affects the properties of bitumen, its viscosity and elasticity in particular (Figure 1).
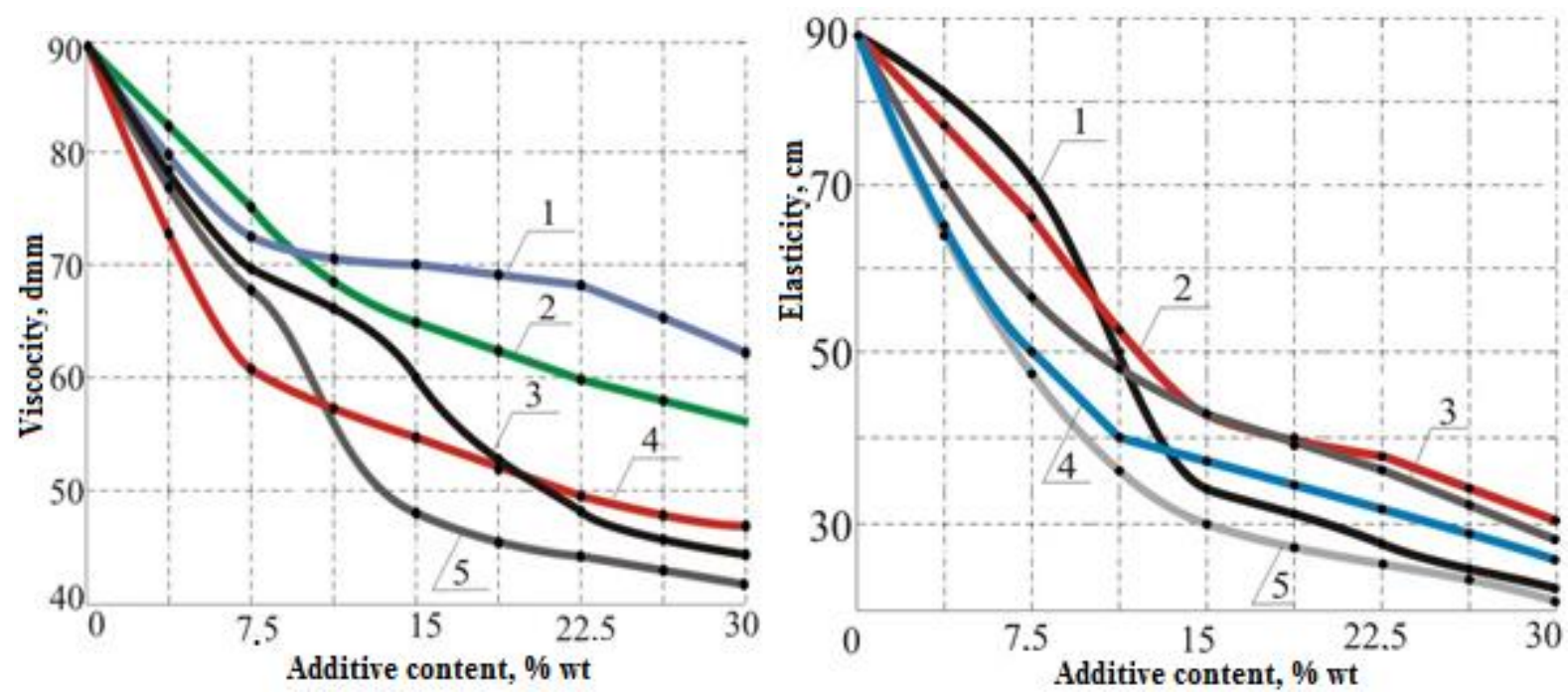

Figure 1. Dependence of bitumen viscosity and elasticity on the content of fine additives from metallurgical waste: 1 - limestone dust, 2 - aspiration dust of the lime production, 3 - converter slag, 4 - microsilica, 5 sinter plant sludge

It should be considered that the optimum composition of asphalt concrete is that comprising the following amounts: filler $-4 \ldots 6 \%$, bitumen $-8 \%$, activator GKZh-11 (ГКЖ-11)-2 .. 3.5\%. The quality of the obtained asphalt concrete is characterized by the following construction and technical properties: water absorption, \% by volume: $2 \ldots 2.2$; water saturation for 15 days $-2.49 \ldots 3$; strength for dry samples $-3 \ldots 3.4$ $\mathrm{MPa}$; compressive strength after prolonged water saturation for 15 days $-3.8 \ldots 4.1 \mathrm{MPa}$. 
The application of cast crushed stone and converter slag crushed stone made it possible to develop various transport structures of roads on the territory of the Lipetsk region. Converter slags belong to active slags, therefore, the application of their 0-10, 0-20, 0-40, 0-70 $\mathrm{mm}$ fractions is justified in the construction of road pavement bases self-hardening while in operation. An example of such a successful implementation is a converter slag fill and a converter slag base for a highway in Mekhanizatorov Street in the city of Lipetsk. The peculiarity of asphalt concrete pavements on such a base is the absence of shear deformations even with dense traffic of heavy vehicles.

The search for road subgrade materials which can be effectively compacted with the existing rolling technologies is among the main tasks of road construction. Thus, a $1 \%$ increase in the compaction degree of a material leads to a10\% increase in the road base strength. It is known that water penetrating into the undercompacted layer of material lowers the durability of both the road subgrade and the road pavement.

An interesting practice of using converter slags as a material for a road subgrade and a fill of variable height up to 15 meters was implemented in Lipetsk (Figure 2).

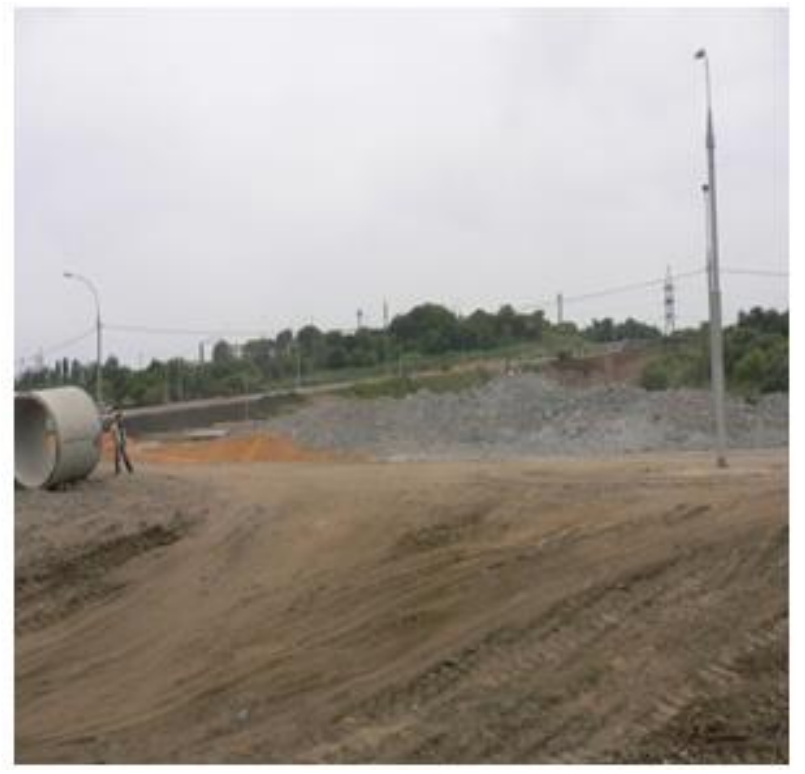

Figure 2. A general view of the road on the $12 \mathrm{~m}$ high converter slag fill

They were used as a sand and crushed stone mix of the $0-10 \mathrm{~mm}$ and $0-90 \mathrm{~mm}$ fractions. In the second fraction, there was $4 \%$ of crushed stone more than $90 \mathrm{~mm}$ in diameter. The converter crushed stone grade was 1200 in strength and F 150 in frost resistance.

The construction site is located in the central part of the city of Lipetsk along Mekhanizatorov Street. Its relief has a southeast gradient towards the Voronezh river with absolute marks ranging from 103.0 to 171.5 $\mathrm{m}$. The soil is loamy with an admixture of chernozem (black soil).

Since part of the road subgrade passes in a fill more than 12 meters high, its stability was calculated in order to determine the geometric parameters. The road subgrade stability in the areas of high fills is analyzed by checking the overall and local stability with account of underflooding. The overall stability was estimated according to two calculation schemes for the loss of stability: landslide-shear deformation -the bistable slope method proposed by N.N. Maslov, failure with shear and rotation - the circular cylindrical failure surface method as modified by Terzaghi (Goncharova et al., 2002; Goncharova and Andriyantseva, 2014).

The overall stability factor equaled 1.28 and the rated safety factor equaled 1.27. As a result of calculations, the overall stability is ensured at variable sloping $1: 1.5 ; 1: 1.75 ; 1: 2$, and resistance to wave action is achieved by strengthening the slope bottom by paving, in other parts the slopes are strengthened by sowing grasses at a double seed rate on the topsoil layer of $15 \mathrm{~cm}$.

The technology of fill and road subgrade pitching included a layer-by-layer expansion of the fill from layers different according to grain composition. The composition of the sand-crushed stone mixture from slags of 
the $0-10 \mathrm{~mm}$ fraction contributed to the increase of the fill material compaction efficiency to the following indicators: the compaction coefficient was 0.98 , and the value of the relative compaction coefficient was 1.5 . In pitching the fill and road subgrade, the physical and mechanical characteristics of the material were monitored. Sampling was performed at five test sites. One year and five years after the operation of the road, samples of converter slags were taken from the fill pits. It was established that the material of the fill is a composite with an average compressive strength of about $7 \mathrm{MPa}$, and tests for its stability against all types of decomposition revealed a medium-stable structure.

The strength of the road pavement design was calculated according to three criteria:

- resistance to stretching when bending asphalt concrete layers;

- resistance to elastic deflection of the whole structure;

- resistance to shear in road subgrade soil and in loosely bound structural layers.

The structural layers of the base were selected on the availability of local road building materials. After calculations on the sections of the fill, the following pavement design was adopted: dense hot asphalt concrete on bitumen BND 90/130, type AI grade $-5 \mathrm{~cm}$; porous hot coarse-grained asphalt concrete on bitumen BND 90/130 - $7 \mathrm{~cm}$; choke crushed stone from NLMK steel-smelting slags of strengthclass1- 24 $\mathrm{cm}$.

Asphalt concretes on slag aggregates have an increased porosity due to the porosity of slag. At the same time, there are open pores on their surface. This leads to the necessity to increase the consumption of bitumen which does not completely fill the pores, especially capillary ones, and asphalt concrete retains a considerable porosity. When wetted, such concrete has an increased swelling ability and insufficient water and frost resistance.

In the present studies, the problem of increasing asphalt concrete density on the basis of slag aggregates was solved in several directions:

- maintenance of the most effective aggregates;

- obtaining filled dense structures of optimum compositions;

- application of separate intensive technologies.

When using aggregates from metallurgical waste, the separate technology implies preliminary intensive mixing of a finely dispersed material with bitumen. In this case, high-speed mixers must be used to mix sludge with bitumen evenly for $30 \ldots 60 \mathrm{~s}$ without lumping or foaming, even when it is introduced as $30 \ldots$ $50 \%$ of the bitumen mass. That is, the technology of asphalt-concrete mix preparation must be intensive and separate. The resulting mixture is homogeneous even at bitumen consumption not exceeding $6 \%$ above $100 \%$ of the mineral mixture in the asphalt concrete composition; it also retains high elasticity with a significant reduction of its viscosity.

\section{CONCLUSION}

In the structural elements of most road subgrades of motor roads in Lipetsk, blast furnace and converter slags were used. The complex indicator of the road pavement condition with respect to use for traffic takes into account a number of characteristics that reflect the efficiency of the material in a structure. The results of determining the coupling properties of road pavements showed that when slag aggregates are used, the coupling properties increase from $45 \%$ to $54 \%$ with slipperiness decreasing from $31.2 \%$ to $22.5 \%$. But special attention must be paid to ensuring proper drainage and production technology compliance.

The implementation of the developed compositions demonstrated good results in the construction of city road pavements in Lipetsk, as well as of the asphalt concrete pavement of the SkornyakovoGagarino3rdcategory road in the Zadonsk district of the Lipetsk region. The correctness of the selected components was proved after one year of operation when the pavement condition was checked: the pavement was preserved without visible defects, cracks and holes.

The implementation of the results of these studies forms the territorial-industrial complex of the region with the developed metallurgical industry (Figure 3). 


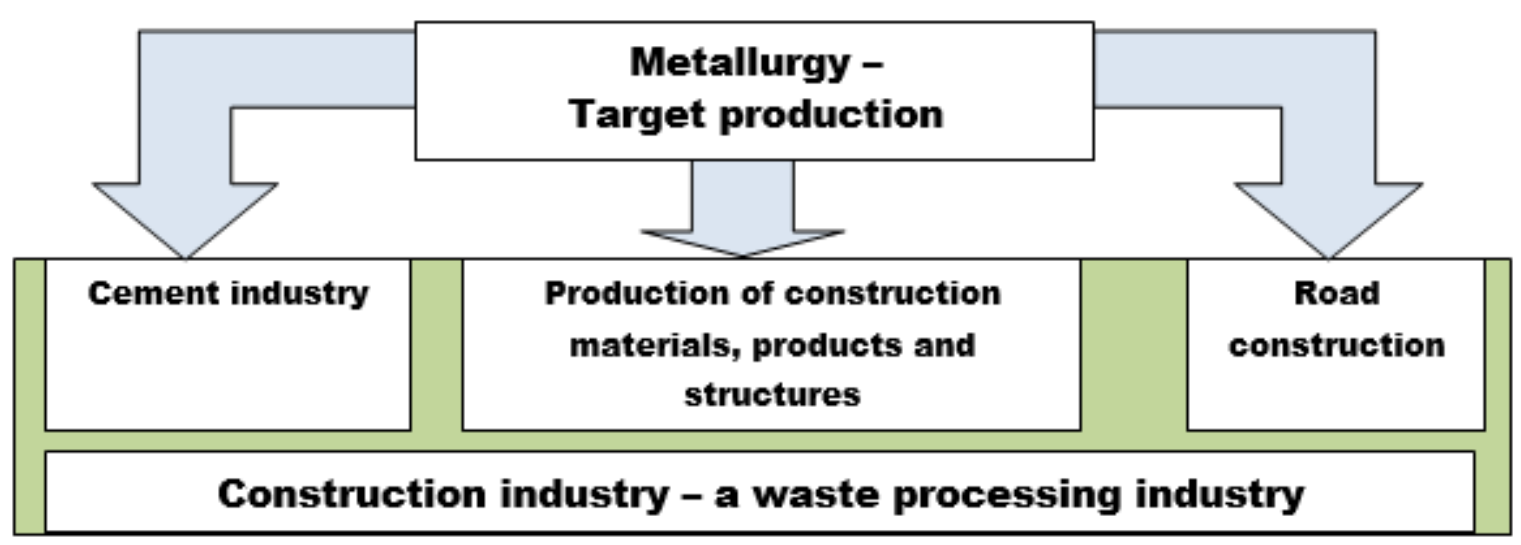

Figure 3. Formation of a territorial-industrial cluster aimed at the construction and technological waste utilization

Thus, focused effort on the application of crystalline slags in road asphalt concretes, despite the limitations of their application, contributes to improving the level of transport and operational condition of roads.

\section{REFERENCES}

B.A. Bondarev, V.Yu. Stefan, L.A. Prozorova, 2016, Complex Quality Control of Stone Mastic Asphalt Concrete on Slag Crushed Stone, R.V. Pershin Publishers, Tambov, (in Russian)

E.M. Chernyshov, M.A. Goncharova, A.D. Korneev, 2009, On the problem of biotechnospheric compatibility of regions with the developed metallurgical industry, in: Construction and Reconstruction. Bulletin of Orel State Technical University, Construction. Transport Series, Issue 573, pp. 68-71. (in Russian)

M.A. Goncharova, A.D. Korneev, O.V. Karaseva, 2015; Prerequisites for hydraulic activity demonstrated by converter slags, in: Vestnik of Russian Academy of Architecture and Construction, Issue 14, Lipetsk State Technical University, Lipetsk, pp. 231-238. (in Russian)

M.A. Goncharova, A.D. Korneev, S.A. Andriyantseva, A.V. Komarichev, 2015, Optimization of construction and technical properties of asphalt concretes by using metallurgical waste, Fundamental Research 2-8, 1620-1625. (in Russian)

M.A. Goncharova, A.V. Kopeikin, V.V. Krokhotin, 2015, Optimization of methods for determining converter slag mineralogical composition, Construction Materials 1, 60-63. (in Russian)

M.A. Goncharova, B.A. Bondarev, A.D. Korneev, 2009, Cristalline metallurgical slags in road construction, Construction materials 11, 23-26. (in Russian)

M.A. Goncharova, B.A. Bondarev, G.E. Stefan, Asphalt Concrete on Slag Fillers, Lipetsk State Technical University, Lipetsk, 2005. (in Russian)

M.A. Goncharova, 2012, Curing Systems and Construction Composites Based on Converter Slags, VGASU, Voronezh. (in Russian)

M. Fakoor, A.Kosari, M. Jafarzadeh, 2015, Revision on fuzzy artificial potential field for humanoid robot path planning in unknown environment, International Journal of Advanced Mechatronic Systems, Volume 6, Issue 4, page 174-183.

Fakoor, M., Kosari, A., Jafarzadeh, M. 2016, Journal of Applied Research and Technology, Journal of Applied Research and Technology, Volume 14, Issue 5, 300-310, 2016.

M.A. Goncharova, I.A. Tkacheva, 2016, A practice of applying stone mastic asphalt concrete with the use of active mineral dust, Construction Materials 10, 80-84. (in Russian)

M.A. Goncharova, I.A. Tkacheva, 2017, Application of adhesive additives to asphalt concrete with granite and slag crushed stone, Construction Materials 11, 39-42. (in Russian)

M.A. Goncharova, N.A. Kashirina, 2016, Forecasting viscous properties of converter slags by analyzing their chemical composition, Actual science 7, 58-60. (in Russian)

M.A. Goncharova, 2008, The application of nanotechnological principles in obtaining slag construction composites, in: Construction and Architecture. Vestnik of Voronezh State University of Architecture and Construction, Issue 11, pp. 61-67. (in Russian) 
M.A. Goncharova, 2014, The use of metallurgical slags in asphalt concrete compositions, in: Modernization and scientific research in the transport complex, Perm National Polytechnic University Publishers, Perm, pp. 395-398. (in Russian)

Ali Khodayari Bavil, Seyed Esmail Razavi, 2017, On the thermo-flow behavior in a rectangular channel with skewed circular ribs, Mechanics \& Industry, 18, 2, 225.

Khosravi, M., Mosaddeghi, F., Oveisi, M. 2015, Aerodynamic drag reduction of heavy vehicles using append devices by CFD analysis, J. Cent. South Univ., 22: 4645.

M.A. Goncharova, B.A.Bondarev, A.D. Korneev, 2002, Construction Composites Based on Slag Waste, Lipetsk State Technical University, Lipetsk, 2002.

M.A. Goncharova, S.A. Andriyantseva, 2014, Composite Materials for Road Construction Based on Technogenic Waste, R.V. Pershin Publishers, Tambov, (in Russian) 